\title{
$\widehat{A}$ Madridge \\ madridge Journal of Nursing \\ nterconnectings
}

Case Report

Open Access

\section{Enhancing End of Life Nursing Education}

\author{
Carol Murch ${ }^{\star}$ and Michael Perlow \\ Murray State University, Murray, KY, USA
}

\section{Article Info}

\author{
*Corresponding author: \\ Carol Murch \\ Murray State University \\ Murray, KY \\ USA \\ E-mail: cmurch@murraystate.edu
}

Received: April 25, 2019

Accepted: May 17, 2019

Published: May 24, 2019

Citation: Murch C, Perlow M. Enhancing End of Life Nursing Education. Madridge J Nurs. 2019; 4(1): 151-154.

doi: $10.18689 / \mathrm{mjn}-1000127$

Copyright: @ $₫ 2019$ The Author(s). This work is licensed under a Creative Commons Attribution 4.0 International License, which permits unrestricted use, distribution, and reproduction in any medium, provided the original work is properly cited.

Published by Madridge Publishers

\begin{abstract}
To determine if an End of Life (EOL) simulation would support pre-licensure nursing students learning about this significant issue an EOL simulation was developed, conducted and evaluated. A group of 43 nursing students completed a pretest, a two hour didactic class on EOL care and then completed an EOL simulation experience. Following the simulation experience the students completed a posttest and evaluated the experience. Post-test scores were significantly higher than pretest scores. The students agreed that the simulation was effective in supporting their learning. Future directions should include further development and examination of the use of simulation for EOL care education.
\end{abstract}

Keywords: Nursing education; End of Life (EOL) care; simulation.

\section{Introduction and Significance}

End of life (EOL) nursing care includes a holistic and sensitive approach to meeting the needs of a patient who is near death. The care is centered upon relieving physical, psychosocial, and spiritual discomforts utilizing an interdisciplinary team approach of health care providers such as the nurse, physician, chaplain, and social worker. Following graduation from nursing school the novice nurses are expected to have learned the concepts of and demonstrated the ability to contribute to the EOL care team. In spite of the many hours of didactic and hospital based clinical education associate degree in nursing (ADN) students fall short of meeting EOL standards for the expected knowledge and practice. In order to facilitate the novice student's preparation nursing faculty must continue to examine strategies to assist the students in meeting their desired learning outcomes and successfully complete the nursing licensure examination, the National Council Licensure Examination-Registered Nurse (NCLEX-RN) [1].

\section{Review of Literature}

An examination of nursing education literature indicated that nursing programs have been inconsistent regarding the inclusion of EOL care within nursing curricula [2]. The National League for Nursing (NLN) [3] and the American Association of Colleges of Nursing (AACN) [2], the two nursing accreditation councils, both offer key resources to faculty for developing nursing curriculum while recommending EOL as desirable student learning outcomes. The AACN developed the End of Life Nursing Education Consortium (ELNEC) to enhance palliative care [2]. ELNEC remains at the forefront of nursing education and demonstrates a genuine focus on improving the effectiveness and quality of nursing education initiatives with a multitude of free educational tools and resources on the organization's website. The organization recommends EOL student competencies which include such things as the learner will advocate for diverse patient populations in efforts to promote self determination and integrity. In addition the ELNEC recommends that the learner will provide safe, quality care throughout the lifespan from birth until death [2]. 
Student nurses receive minimal to no clinical experiences dealing with EOL care depending on their particular program and clinical experience. As a direct result of these inconsistent and often inadequate EOL clinical experiences, new graduates have expressed the feeling of not being prepared to facilitate communication and provide adequate care at the time of death. Students who have achieved EOL student learning outcomes within the curricula expressed having had an opportunity for EOL lecture and clinical experiences as well as an opportunity to demonstrate compassionate communication and nursing care to patients who were dying [4].

The use of a patient simulation experience can offer education to students in a controlled and safe environment either on the college campus or the education department. "Simulated experiences have been shown to be particularly beneficial when dealing with emotionally charged issues like end-of-life care and this (teaching) modality allows students to practice the assessment of the physiological changes taking place in the dying patient and the necessary patient care decisions" [5]. According to a study by the NCSBN, the replacement of off-campus clinical hours with $50 \%$ lab-based simulation revealed that no statistical difference existed for students in meeting program outcomes and success on the national licensure exam as compared with the hospital based clinical experience [6].

\section{Methodology}

\section{Purpose of the experience}

Students will continue to require knowledge regarding EOL care. This awareness and utilization must be carried out all of the learning domains, the cognitive, psychomotor and affective. Given the common minimal provision of specific EOL content and clinical experience it is a reasonable supposition that these novice graduates will continue to not be prepared to carry out their duties in an essential area of nursing care. Typically any EOL content is provided within a one or two hour didactic presentation about death and dying. Along with the minimum exposure to this important content clinical exposure to the EOL issues is either episodic or often non-existent. Nursing simulation scenarios exist that cover a wide variety of nursing experiences. However none of the current, commercially available simulations consider the process of EOL care $[6,7]$.

The overall purpose of this project was to develop, implement, and evaluate an innovative, approach to provide EOL didactic content along with a dedicated, EOL clinical simulation experience. The project question considered the issue as to whether direct didactic clinical instruction and an EOL simulation experience improve student nurses' knowledge of and perceived competence with EOL care? The project query was consider whether the use of an EOL simulation scenario lead to an increased understanding and perceived competence in caring for a dying patient.

\section{Project scheme}

The project consisted of a pre-test post-test single group examination of a two phase approach to EOL education. The students completed a two hour didactic education class that addressed specific tenets of EOL education. This didactic instruction is not a usual aspect of the nursing curriculum and was provided to determine whether specific EOL content would improve understanding of that material.

In addition the students participated in an instructor created EOL simulation which also addressed the tenets of EOL issues that nurses will likely come across in their practice. Groups of five students completed this simulation and worked through the process together.

A convenience cohort of 43 pre-licensure nursing students volunteered and were provided an EOL education in a didactic setting. These students initially completed a pretest on EOL content and then completed a two hour EOL simulation experience. Each student then completed a post-test on the same EOL content. In addition each student completed a completed a questionnaire that evaluated the effect the experience had on their learning and overall education regarding $\mathrm{EOL}$ content.

\section{Evaluation instruments}

Both the EOL pre-test/post-test and the summative questionnaire for EOL simulation evaluation were created by the authors. The ten pre-test/post-test questions were written based upon the basic level of nursing knowledge, understanding, and critical thinking skills necessary for providing quality EOL care. The blueprint for the questions was created from the recommendations for EOL care from the NCSBN and the AACN ELNEC Project [6,7]. The specific topics addressed in the pre-test/post-test included the living will; differences between curative and palliative care; and roles of the nurse as the patient nears death.

The EOL Survey Evaluation included a summative selfreport consisting of 9 statements that were evaluated using a Likert type scale to determine each student's agreement with statements regarding the experience. An additional area for any open response was also provided. Particular statements addressed the application of knowledge; benefit of the experience; effect of the experience on critical thinking, communication, and knowledge (Table 1).

Table 1. Simulation Survey Ratings and Responses Analysis.

\begin{tabular}{|c|c|c|c|c|c|}
\hline &  & 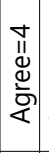 & 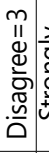 & 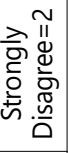 & 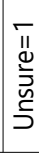 \\
\hline \begin{tabular}{l|l}
1 & $\begin{array}{l}\text { f feel this exercise has helped me to apply } \\
\text { knowledge rather than just memorizing content. }\end{array}$
\end{tabular} & (16) & (2) & & & \\
\hline $2 \begin{array}{l}\text { I learned something beneficial through this } \\
\text { simulation of caring for a dying patient and her family. }\end{array}$ & (16) & (2) & & & \\
\hline $\begin{array}{l}3 \\
\begin{array}{l}\text { This simulation enhanced my critical thinking skills } \\
\text { for providing EOL nursing care. }\end{array}\end{array}$ & (18) & & & & \\
\hline $\begin{array}{l}4 \text { The simulation was facilitated smoothly by Mrs. } \\
\text { Carol Murch. }\end{array}$ & $(15)$ & (3) & & & \\
\hline 5 This simulation promoted communication skills. & (13) & (5) & & & \\
\hline $6 \begin{array}{l}\text { I feel that I've had a safe environment to share my } \\
\text { ideas and thoughts. }\end{array}$ & (18) & & & & \\
\hline $7 \begin{array}{l}\text { The simulation was beneficial to my nursing } \\
\text { education. }\end{array}$ & $(18)$ & & & & \\
\hline $8 \begin{array}{l}\text { The simulation helped to uncover some knowledge } \\
\text { deficiencies in myself. }\end{array}$ & $(17)$ & (1) & & & \\
\hline 9 The supplies needed were readily accessible. & $(15)$ & (3) & & & \\
\hline
\end{tabular}




\section{Comments:}

- Very educational! I appreciate the extra knowledge and learning experience!

- This was a great simulation. It certainly was interesting, and it definitely enhanced my nursing skills.

- This simulation was very beneficial \& I feel I learned a lot of information I might not have been given a chance to outside of a simulation such as this.

- I really appreciated the interactive section \& debriefing. I learned so much.

- I was very pleased with the set up and how real it felt.

- Need flip cards turned over on cubicle to know what time it was noting the next part of the scenario.

- Need a more efficient way to know [what] time it is such as synchronizing watches or clock set with simulation time.

\section{End of life nursing simulation scenario}

The End of Life Nursing Simulation Scenario was designed following a review of the National League for Nursing [3] and the Commonwealth of Kentucky's ADN program requirements [8]. The primary author who had experience in the development of simulation over the previous eight years prepared the simulation. This author is a Certified Hospice and palliative Nurse and completed the American Academy of Colleges of Nursing ELNEC Educators Training Modules.

The End of Life Nursing Simulation Scenario was designed to last two hours and included five nursing student roles so that each session could include no more than five participants. The End of Life Nursing Simulation Scenario, included the objectives, the educational design for the experience, a simulation timeline, supplies/equipment list, the simulated patient medical record along with a health history, physician orders, medication administration record, the scripted (prerecorded) dialogue for the characters of patient/family members, and a debriefing guideline. The simulation development phase of the project took approximately five months to complete.

\section{Findings, Conclusions and Recommendations}

All 43 students completed both the pre-test and the post-test. Each of the students improved their pre-test scores. The pre-test scores ranged from $4 / 10$ (40\%) to $9 / 10(90 \%)$ while the post-test scores ranged from $9 / 10$ (90\%) to $10 / 10$ (100\%). Each of the students completed the EOL simulation experience survey describing the experience each item as either strongly agree or agree. A review of the open-ended responses revealed that 7 individuals provided a separate comment about the experience. Five of the comments were positive. The two responses that were critical involved difficulty in identify the time from of the experience as the experience was progressing (Table 2).
Table 2. Pre/post-Simulation Quiz Score Comparison Chart and Cumulative Signed-Rank Test Analysis.

\begin{tabular}{|c|c|c|c|}
\hline $\begin{array}{c}\text { Study participant } \\
\text { Number }\end{array}$ & $\begin{array}{c}\text { Pre-simulation } \\
\text { Quiz score }\end{array}$ & $\begin{array}{c}\text { Post-simulation } \\
\text { Quiz score }\end{array}$ & \\
\hline 1 & $8 / 10$ & $10 / 10$ & \\
\hline 2 & $6 / 10$ & 9/10 & \\
\hline 3 & $6 / 10$ & $10 / 10$ & \\
\hline 4 & $5 / 10$ & $10 / 10$ & \\
\hline 5 & $4 / 10$ & $10 / 10$ & \\
\hline 6 & $9 / 10$ & $10 / 10$ & \\
\hline 7 & $8 / 10$ & $10 / 10$ & \\
\hline 8 & $8 / 10$ & $10 / 10$ & \\
\hline 9 & $7 / 10$ & $10 / 10$ & \\
\hline 10 & $6 / 10$ & $10 / 10$ & \\
\hline 11 & $6 / 10$ & $10 / 10$ & \\
\hline 12 & $5 / 10$ & $10 / 10$ & \\
\hline 13 & $5 / 10$ & $10 / 10$ & \\
\hline 14 & $8 / 10$ & $10 / 10$ & \\
\hline 15 & $5 / 10$ & $10 / 10$ & \\
\hline 16 & $7 / 10$ & $10 / 10$ & \\
\hline 17 & $6 / 10$ & $10 / 10$ & \\
\hline \multirow[t]{2}{*}{18} & $8 / 10$ & $10 / 10$ & \\
\hline & $\begin{array}{c}M=6.50 \\
S D=1.424\end{array}$ & $\begin{array}{l}M=9.944 \\
S D=.235\end{array}$ & $\begin{array}{c}\text { Signed-Rank Test: } \\
D=\text { Post-Pre Quiz } \\
H_{0}: M_{D}=0 \\
H_{A}: M_{D}=>0 \\
\alpha=0.05 \\
T+=171 \\
T-=0 \\
T=0 \\
p=.0001982^{*} \\
\text { * } p \text { is significant } \leq 0.05\end{array}$ \\
\hline
\end{tabular}

The overall examinations of the project outcomes were positive. The findings provided support that the End of Life Nursing Simulation Scenario was an effective educational approach to achieve student EOL learning outcomes. That the use of simulation in EOL supports learning of this difficult to obtain clinical experience is a positive finding for providing clinical education for pre-licensure nursing students.

Most certainly additional research need be completed focusing on the role of simulation in EOL education. Creation of additional EOL simulations should be undertaken as well as making EOL experiences available to a variety of nurse educators (Figure 1).

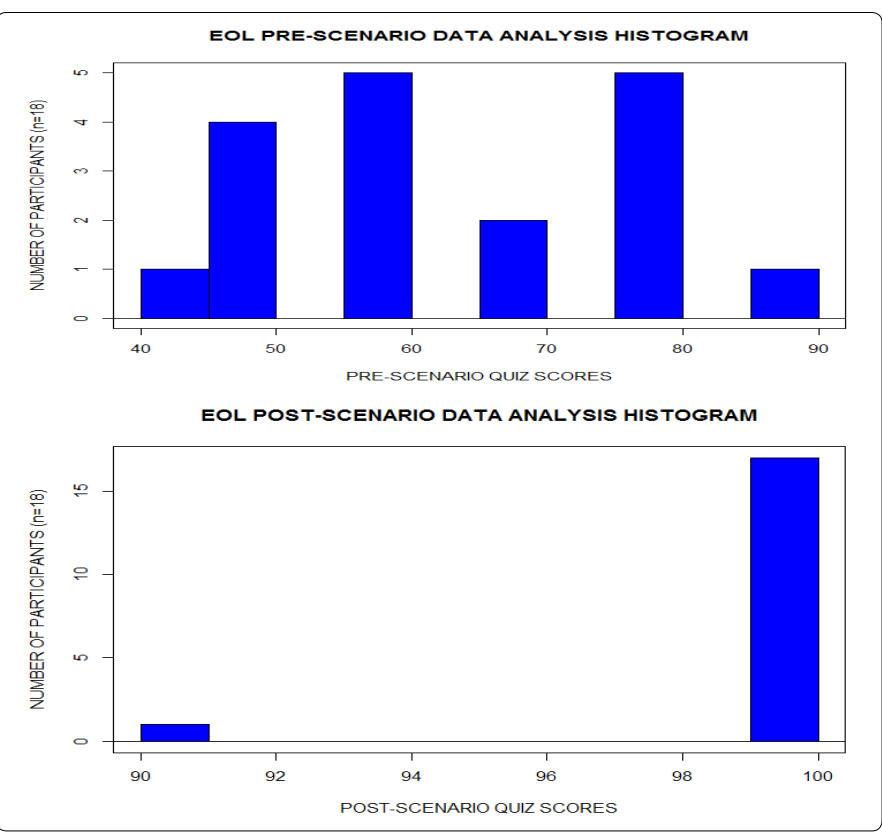

Figure 1. Pre/post-Simulation Quiz Score Histogram Graphs. 


\section{References}

1. National Council of State Boards of Nursing. National council licensure examination- Registered nurse. 2015.

2. American Association of Colleges of Nursing. Peaceful death: Recommended competencies and curricular guidelines for end-of-life nursing care. 2015.

3. National League for Nursing. Competencies for graduates of nursing programs. 2013.

4. Welsh D, Lowry RC. Nursing students and end-of-life care: A play. Nurs Educ Perspect. 2011; 32(6): 414-416.
5. Kaddoura MA. New graduate nurses' perceptions of the effects of clinical simulation on their critical thinking, learning, and confidence. J Contin Educ Nurs. 2010; 41(11): 506-516. doi: 10.3928/00220124-20100701-02

6. Hayden JK, Smiley RA, Alexander M, Kardong-Edgren S, Jeffries PR. The NCSBN national simulation study: A longitudinal, randomized, controlled study replacing clinical hours with simulation in prelicensure nursing education. Journal of Nursing Regulation. 2014; 5(2): 1-66.

7. Hospice and Palliative Nurses Association. Position statement: Evidencebased practice. 2012.

8. Kentucky Legislative Research Commission. Standards for curriculum of prelicensure nursing programs: 201 KAR 20:320. 2014 